\title{
Uma leitura de Verdade e Política de Hannah Arendt: o contextualismo social altera o sentido da teoria política arendtiana?
}

\author{
Mariana da Silva Pereira \\ Vania Sandeleia Vaz da Silva
}

\begin{abstract}
Resumo: O contextualismo social - ou história social da Teoria Política - é um método de leitura e análise de textos que tem como intuito interpretar de forma mais substantiva e completa as ideias de teóricos da política, sendo esses compreendidos como "atores" políticos, engajados nos conflitos e problemas sociais da época e do lugar em que viveram. Tal abordagem metodológica parte da premissa de que não é possível compreender adequadamente o significado de um texto de Teoria Política sem considerar o seu contexto imediato de produção, considerando necessário somar, à análise textual, conhecimentos sobre a biografia, bem como dos aspectos políticos, econômicos e culturais da sociedade em que o autor viveu e escreveu. O presente trabalho consistiu na aplicação do referido método à leitura do ensaio "Verdade e Política" (1967) escrito por Hannah Arendt, procurando investigar se realizar a contextualização social da autora altera o entendimento a respeito do significado do texto. Em comparação com a abordagem normativa, ou textualista, de leitura de textos clássicos da Teoria Política, os resultados obtidos com essa pesquisa levaram a questionar a imprescindibilidade da contextualização social para uma interpretação adequada da mensagem contida nesse ensaio.
\end{abstract}

Palavras-chave: Contextualismo Social; Verdade e Política; Hannah Arendt; Ellen Meiksins Wood; Neal Wood.

\section{A reading of Hannah Arendt's Truth and Politics: does social contextualism change the meaning of arendtian political theory?}

\begin{abstract}
Social contextualism - or the social history of political theory - is a method of reading and analyzing texts that aims to interpret in a more substantive and complete way the ideas of political theorists, who are understood as political "actors", engaged in conflicts and social problems of the time and place where they lived. This methodological approach is based on the premise that it is not possible to properly understand the meaning of a text of political theory without considering its immediate context of production, considering it necessary to add, to the textual analysis, knowledge about the biography, as well as the political, economic and cultural aspects of the society in which the author lived and wrote. The present work consisted in the application of the referred method to the reading of the essay "Truth and Politics", of 1967, of Hannah Arendt, trying to investigate if making the author's contextualization changes the understanding about the meaning of the text. In comparison with the normative, or textualist, approach to reading classic texts from Political Theory, the results obtained with this research led to question the indispensability of social contextualization for an adequate interpretation of the message contained in this essay.
\end{abstract}

Keywords: Social contextualism; Truth and Politics; Hannah Arendt; Ellen Meiksins Wood; Neal Wood.

\footnotetext{
${ }^{1}$ Graduada em Licenciatura em Ciências Sociais (UNIOESTE), mestranda em Filosofia Política (UNIOESTE). E-mail: mariisdp7890@gmail.com.

${ }^{2}$ Graduada em Ciências Sociais (UFPR), Mestra e Doutora em Ciência Política (USP), professora no curso de Ciências Sociais na Unioeste, Campus de Toledo. E-mail: vaniasandeleiavazdasilva@yahoo.com
} 


\section{Introdução}

"Contextualismo Social" foi o nome atribuído pelo Grupo de Pesquisa Democracia e Desenvolvimento - ligado ao curso de Ciências Sociais da Unioeste, Campus de Toledo - à "história social da Teoria Política" - método de leitura e análise de textos clássicos de Teoria Política, elaborado em parceria por Neal Wood e Ellen Meiksins Wood. Tal abordagem consiste na realização de uma meticulosa "contextualização" acerca dos autores a serem estudados e suas respectivas obras.

Parte-se da premissa de que não é possível compreender adequadamente o significado de um texto de Teoria Política sem considerar o seu contexto social de produção; isso significa que, para interpretar as ideias de um determinado teórico, seria necessário um conhecimento complexo dos aspectos políticos, econômicos e culturais da sociedade em que ele viveu e escreveu. Segundo Cardoso, Silva e Neres (2016), um teórico da política deve ser considerado um "ator" político que esteve engajado nas lutas e conflitos reais de sua época e lugar.

A discussão sobre "por que" e "como" estudar Teoria Política surge em meio a um cenário de desvalorização e hostilização das formas de conhecimento político que não fossem objetivas e adquiridas empiricamente. Em meados do século XX, a Ciência Política se consolida como uma disciplina autônoma e o behaviorismo é reconhecido como novo paradigma científico. Os behavioristas defendiam uma proeminência do presente sobre o passado e do empírico sobre o teórico. Assim, o conhecimento sobre a política cindiu-se entre "teórico" e "empírico", estabelecendo uma dicotomia fundamental entre Teoria Política e Filosofia Política, de um lado e Ciência Política de outro.

Intelectuais das mais variadas correntes teóricas tentaram devolver a dignidade ao estudo da História das Ideias da Teoria Política e da Filosofia Política - àquele momento visto como "secundário" e "cristalizado". Entre elas, destacam-se: a abordagem normativa, ou textualista, representada principalmente por Leo Strauss, que entendia que o significado de um texto deveria ser procurado nele mesmo, por meio de uma leitura "atenta"; o historicismo radical, ou contextualismo linguístico, da Escola de Cambridge, cujo maior expoente foi Quentin Skinner, defendendo que, para compreender o significado de um texto, seria necessário reconstruir o seu contexto linguístico e intelectual de produção; e a história social da teoria política, ou contextualismo social, desenvolvido e aplicado por Neal Wood e Ellen Meiksins Wood, cuja compreensão é de que um texto de Teoria Política só poderia ser adequadamente compreendido e interpretado mediante o conhecimento do contexto social do autor que o escreveu porque esse o fez por estar engajado nos conflitos reais e práticos de sua época, com interesses particulares.

O presente trabalho caracterizou-se por uma reflexão a respeito da aplicação do contextualismo social ao ensaio "Verdade e Política", de 1967, da pensadora Hannah Arendt, tendo como base as orientações feitas por Silva (2016). A pergunta que fundamentou essa investigação foi "A aplicação do contextualismo social altera a compreensão desse texto?", a qual se procurou responder da seguinte forma: primeiro, apresenta-se, detalhadamente, a discussão a respeito de "por que" e "como" estudar Teoria Política; depois, uma breve introdução sobre o que é o contextualismo social; em terceiro lugar, realizou-se a contextualização social de Arendt; em quarto lugar, expôs-se a análise textual de "Verdade e Política"; e, por fim, discutiu-se os resultados obtidos comparando essa abordagem metodológica com outras já mencionadas, fundamentalmente com o textualismo de Strauss.

\section{Por que e como estudar Teoria Política?}

As perguntas "por que estudar os textos clássicos da Teoria Política?" e "como eles devem ser estudados?" emergem em meio a um intenso, e bastante polêmico, debate a respeito da identidade da Teoria Política, enquanto disciplina, o qual começa a se desenvolver na segunda metade do século XX, com a autonomização da Ciência Política em relação ao conhecimento teórico sobre a política. 
O que se aventava, naquele momento, era a necessidade de um conhecimento empírico e objetivo sobre a política, o que conduziu a Filosofia Política e a História das Ideias a uma posição de inferioridade na produção de conhecimentos sobre a política (PEREIRA, 2018, p. 11).

Nesse contexto, o estudo da história do pensamento político foi alvo de constantes críticas e reformulações metodológicas. Tal discussão conduzia à necessidade de definir o que é Ciência Política, Filosofia Política e a Teoria Política, como a concebemos atualmente - isto é, quais são as particularidades que distinguem essas formas de conhecimento sobre a política e qual a relevância de cada uma delas.

Como salientou Silva (2008), já no começo da década de 1950, David Easton, o maior expoente do behaviorismo, lamentava a insuficiência da Teoria Política para impulsionar o desenvolvimento do conhecimento científico da política. Para ele, o empobrecimento da disciplina se devia à sua predominante "abordagem histórica" que ajudava a desviar o foco dos problemas empíricos do presente e da tarefa de construir uma teoria sistemática sobre o comportamento político e as instituições políticas. Easton compreendia que esse tipo de "historicismo" se ocupava de descrever como a ordem social deveria ser e ignorava como ela, de fato, é. "Resumidamente, os behavioristas defendiam uma proeminência do presente sobre o passado, do empírico sobre o teórico e da "neutralidade" sobre a normatividade" (SILVA, 2008, p. 11).

A corrente representada principalmente por Easton permaneceu minoritária até 1966, quando Gabriel Almond, presidente da Associação Americana de Ciência Política, reconheceu o behaviorismo como novo paradigma científico, estabelecendo uma dicotomia fundamental entre Teoria Política - que passou a ser compreendida como a história do pensamento político - e Ciência Política - a análise empírica das instituições políticas, baseada numa epistemologia positivista (AMADEO, 2011).

A consolidação da nova Ciência Política, a separação entre os estudos normativos - ou teóricos - e empíricos - ou "científicos" - sobre a política, bem como o pronunciamento de Almond a respeito do behaviorismo configuraram um cenário hostil, tanto para a Teoria Política quanto para a Filosofia Política - disciplinas que foram profundamente desvalorizadas e rotuladas como "pré-científicas".

A percepção generalizada de que a Filosofia Política e a Teoria Política se encontravam em "declínio" pode ser interpretada, conforme Pereira (2016), como o pivô de uma produção intelectual muito rica, impulsionando os esforços de diversos pensadores para recuperar a dignidade dos estudos teóricos sobre a política.

Leo Strauss, parte da corrente teórica identificada como normativa, respondeu às acusações de insignificância da Filosofia Política arguindo que estudar o pensamento político do passado era importante para obter uma adequada compreensão dos fenômenos políticos modernos, assim como para a iluminação e solução de problemas políticos contemporâneos (GUNNEL, 1981). Da mesma forma como Isaiah Berlin, Hannah Arendt, Eric Voegelin, Sheldon Wolin e outros, Strauss interpretava o quadro da Ciência Política, da Filosofia Política e da Teoria Política, daquele momento, como sintoma de uma crise intelectual, baseada no declínio da tradição do pensamento político ocidental, identificando o início dessa tradição com Platão e Aristóteles e o seu fim, principalmente, com as teorias de Marx e Nietzsche (PEREIRA, 2018).

De acordo com Pereira e Silva (2018), entre esses pensadores, Strauss ocupa posição de destaque por ter se dedicado a responder sistematicamente às seguintes questões: qual é o significado de "tradição" ou o que se entende por "tradição"? Qual é a importância de estudar os textos clássicos do pensamento político? Quais os critérios que devem ser usados na interpretação desses textos?

O método de análise de textos clássicos representado por Leo Strauss ficou conhecido como "textualismo", por consistir, de acordo com seus críticos, na leitura "repetitiva" dos textos que compõem o cânone do pensamento político Ocidental. Leo Strauss defendia a necessidade de uma leitura "atenta" do próprio texto, ou seja, uma abordagem tradicional de estudo dos textos clássicos, também chamada de modo filosófico de análise, compreendendo que o significado de um texto deve ser encontrado nele 
mesmo, por meio de uma análise cuidadosa da própria obra, sem a necessidade de recorrer a fontes bibliográficas externas e de reconstituir um contexto, seja ele social ou intelectual.

Strauss desenvolveu estratégias metodológicas que permitiriam decodificar o significado das obras de Filosofia Política, compreendendo que essas poderiam conter mensagens ocultas caso fossem escritas sob risco de perseguição. A filosofia, quando expressa publicamente, pode se tornar uma ameaça por proferir verdades heterodoxas àquelas que são aceitas socialmente (PEREIRA; SILVA, 2018). Na concepção de Strauss, essa perseguição poderia dar origem a uma técnica particular de escrita, na qual o verdadeiro ensinamento é proferido somente nas entrelinhas.

A abordagem de Leo Strauss foi severamente criticada por Quentin Skinner - que a chamou de textualista. Skinner considerava que os resultados obtidos com o uso do método tradicional não poderiam ser chamados, efetivamente, de "história", visto que, para compreender sociedades anteriores à nossa, é necessário recuperar as suas "mentalidades" da forma mais integral possível, por meio da reconstituição do "contexto" no qual emergiram as obras a serem analisadas.

Quentin Skinner é um dos nomes de maior destaque entre os historiadores da Universidade de Cambridge, por ser quem organizou e sistematizou a metodologia de leitura dos textos clássicos do pensamento político conhecida como "historicismo radical", ou contextualismo linguístico. Conforme Pereira (2016), as proposições metodológicas skinnerianas se apresentaram como um caminho alternativo no cenário polarizado entre as correntes behaviorista e normativa. Para Skinner, a importância de estudar os textos clássicos da Teoria Política reside em que as lições do passado sirvam para "excitar a nossa criatividade na busca pela solução de nossos próprios problemas" (PEREIRA, 2016, p. 58), ajudandonos a distinguir o que é essencial do que é contingencial.

O historicismo radical enfatizava a importância de se recuperar a "intenção" do autor, isto é, aquilo que ele quis dizer quando disse o que disse, o que leva a apelar à historicidade e analisar o contexto no qual determinada obra é produzida, segundo Amadeo (2011). Skinner considerava que era o contexto linguístico e intelectual que deveria ser recuperado para a compreensão adequada de um texto, entendendo que palavras são atos. Para captar as intenções autorais, ele elabora a noção de "significado" (meanings), porque, se as palavras são atos, elas devem representar alguma coisa para quem as utiliza e essa pessoa, por sua vez, deve ser refém de jogos de linguagem que correspondem a um determinado período histórico.

Como ressalta Pereira e Silva (2019), embora a proposta skinneriana pareça ser mais completa e adequada do que a abordagem textualista de Leo Strauss, foi também criticada porque não recuperava todo o contexto social em que as obras foram produzidas, já que enfatizava o contexto intelectual ou ideológico. Enquanto o método de estudo da teoria política proposto por Leo Strauss necessita apenas da própria obra e de um leitor atento - ou inteligente - e da compreensão de que a mensagem poderá estar nas entrelinhas. O contextualismo linguístico de Quentin Skinner já exige a leitura de outras obras escritas no mesmo período - para a reconstituição do contexto intelectual ou ideológico - e também de estudos históricos a respeito da sociedade em que o autor viveu e escreveu - para identificar quais eram as "questões" que estavam sendo respondidas.

Neal Wood, junto com sua parceira, Ellen Meiksins Wood, elaborou outra abordagem para análise dos textos clássicos do pensamento político, a qual chamou de "história social da Teoria Política", consistindo na realização da contextualização mais completa acerca dos autores a serem estudados e suas respectivas obras. Cardoso, Silva e Neres (2016) afirmam que tal empreendimento é, por essa razão, um método de leitura mais exigente, que vê o autor como um ator político engajado nas lutas e conflitos reais de sua época e lugar, sendo composto pela reconstrução do contexto social em que o pensador viveu e escreveu, bem como de sua biografia, somadas a uma análise profunda de sua obra. Além disso, tal abordagem promete permitir identificar quais das ideias articuladas em determinado texto possuem um valor "universal" e quais delas são completamente contingentes. 


\section{A proposta do Contextualismo Social}

A "história social da Teoria Política", enquanto método de leitura de textos clássicos, foi proposta por Neal Wood em The Social history of political theory, de 1978; extensivamente aplicado, por Ellen Meiksins Wood no estudo dos clássicos do pensamento político; e discutido detalhadamente, em comparação a outras abordagens metodológicas, por Neal Wood, no livro Reflections on Political Theory: a voice of Reason from the past, de 2002, em que enfatiza sua adesão a uma vertente marxista de análise textual (SILVA, 2016). A partir das exposições de Neal Wood em um artigo publicado em 1978, intitulado "The social history of political theory", Silva (2016) destacou um conjunto de questões relevantes para realizar a contextualização social da Teoria Política, partindo da pressuposição de que:

(1) a política é um empreendimento eminentemente prático, enraizado na vida cotidiana e preocupado com as relações entre indivíduos e grupos sociais que agem na arena pública visando sua sobrevivência e normalmente buscando sua própria vantagem em nome do interesse público ou do bem comum; (2) a teoria política clássica está intimamente relacionada com o contexto social e histórico prático no qual foi concebida; (3) cada texto clássico de teoria política, entre outras coisas, é uma importante reflexão sobre o seu tempo, dizendo-os muito sobre a natureza da sua sociedade particular; (4) a gênese de uma obra clássica de teoria política pode ser explicada em termos sociais, representando fundamentalmente uma posição partidária no conflito do período; (5) consequentemente, toda obra clássica de teoria política é ideológica, embora não exclusivamente [...] (SILVA, 2016, p. 89)

A história social da Teoria Política tem como premissa que o significado de um texto só pode ser adequadamente compreendido quando interpretado à luz dos problemas políticos e sociais que marcaram contexto de produção. Esse "contexto", de acordo com Cardoso, Silva e Neres (2016), engloba tanto o conhecimento complexo de aspectos políticos, econômicos e culturais da sociedade em que o autor viveu e escreveu, como também a profunda análise da obra, não se restringindo à análise do contexto intelectual e linguístico. A abordagem de Neal Wood e Ellen Meiksins Wood pretende que o autor da obra seja considerado "um 'ator' político engajado nas lutas e conflitos reais de sua época e lugar" (CARDOSO; SILVA; NERES, 2016, p. 77) e, por isso, a interpretação de suas ideias deve estar relacionada à sua biografia, bem como à situação política de sua época.

Para o contextualismo social ${ }^{3}$, o "contexto" que procura reconstituir difere e ultrapassa outras metodologias contextualistas - como a proposta skinneriana ou a contextualização marxista ortodoxa abarcando maior escopo de especificidades históricas. A preferência pelo método se deu em função do pressuposto de que todos os teóricos clássicos da política estiveram engajados ativamente nos conflitos sociais de sua época, assumindo uma "posição", a partir da qual pensaram o seu objeto e defenderam os seus "interesses". Considera-se que a compreensão do contexto social de um pensador desse tipo seja uma etapa essencial na interpretação de suas ideias.

Silva (2016), ainda, esboçou um roteiro com diversas questões que podem ser usadas para facilitar a contextualização social de autores e obras, ressaltando que alguns casos exigem que outros elementos sejam analisados para compreender a relação entre as ideias políticas de determinado pensadores e o contexto no qual viveu, escreveu e atuou e que, em outros casos, pode ser impossível responder a todas essas questões. Tal roteiro foi organizado em tabelas, nas quais estão dispostas e agrupadas perguntas que servem como "guia" para uma análise conforme o contextualismo social.

\footnotetext{
3 A opção por chamar tal abordagem de "contextualismo social" ocorreu nas discussões realizadas pelo Grupo de Pesquisa em Democracia e Desenvolvimento, vinculado ao curso de Ciências Sociais da Universidade Estadual do Oeste do Paraná (UNIOESTE), campus de Toledo.
} 


\section{A contextualização social de Hannah Arendt e do ensaio "Verdade e Política" publicado em $1967^{4}$}

A presente pesquisa teve como uma de suas etapas a realização da contextualização social de Hannah Arendt e do ensaio intitulado "Verdade e Política", seguindo o roteiro proposto por Silva (2016). Sendo assim, procurou-se responder as questões referentes a: (1) aspectos do contexto social em que o autor escreveu a obra em análise, a fim de compreender como suas ideias de relacionam com a estrutura de classes e o conflito social; (2) aspectos relacionados à biografia que permitem situar o autor na sociedade; (3) aspectos relacionados ao ideal humano do autor, ou seja, seu "herói" e "anti-herói"; (4) as prescrições para a realização do ideal humano; (5) a delimitação da especificidade histórica das ideias do teórico; (6) identificação das estruturas básicas dos argumentos utilizados pelo autor, buscando delinear suas implicações e contradições; (7) identificação dos destinatários do autor.

\section{Aspectos do contexto social ${ }^{5}$}

Hannah Arendt publicou o ensaio intitulado "Verdade e Política" pela primeira vez em The New Yorker, em fevereiro de 1967 e integrado ao livro "Entre o passado e o futuro", no ano seguinte.

De acordo com Rockman (1994), entre as décadas de 1950 e 1960, nos Estados Unidos, os partidos políticos possuíam estruturas fortemente organizadas localmente, mas muito fracas nacionalmente e as coalizações internas dentro de cada partido eram repletas de contradições. $\mathrm{O}$ eleitorado Democrata, por exemplo, "era composto por intelectuais de esquerda, máquina local urbana das organizações patronais, minorias raciais no norte, segregacionistas sulinos, sindicatos de trabalhadores e grupos étnicos europeus" (ROCKMAN, 1994, p. 54). O eleitorado Republicano, embora mais simples, também possuía conflitos que giravam "em torno das pequenas cidades americanas e os centros financeiros, principalmente Wall Street em Nova Iorque” (ROCKMAN, 1994, p. 54). Além disso, ele ressalta que de 1953 a 1993 houve uma queda constante da participação política da população no processo eleitoral, ao mesmo tempo que se expandia o número de eleitores.

Outro aspecto importante é que os líderes de partido no Congresso, na década de 1950, eram figuras poderosas, ou seja, personalidades fortes e influentes, mas com poder formal relativamente, o que os levava a negociar e a barganhar com os presidentes das comissões; e a Coalizão Conservadora, que abrangia Republicanos e a maioria Democrata conservadora do sul, ganhou importância e fez-se proeminente, detendo o poder central pela maior parte do tempo, nas décadas de 1950 e 1960 (ROCKMAN, 1994).

Destaca-se, ainda, que o período no qual Arendt produz a maior parte de sua obra é sucedâneo da Segunda Guerra Mundial e ficou conhecido como "Guerra Fria" - momento histórico em que a política internacional estava fortemente polarizado, entre Estados Unidos da América e União das

\footnotetext{
${ }^{4}$ Foram utilizadas, como fontes de consulta, para o desenvolvimento dessa parte da pesquisa, os prefácios e posfácios dos livros "A Vida do Espírito", "A Condição Humana”, "Entre o Passado e Futuro" e "O que é Política”, de Hannah Arendt, bem como as correspondências trocadas e entre Arendt e Heidegger, compiladas no livro "Hannah Arendt e Martin Heidegger - Correspondências 1925/1975”, organizado por Ursula Ludz; e algumas fontes secundárias.

${ }^{5}$ As questões da Tabela 1 - “aspectos relacionados ao contexto social em que o autor escreveu a obra em análise, que permitem compreender como suas ideias se relacionam com a estrutura de classes e o conflito social”, são: 1) Quais classes estão ascendendo e quais estão declinando? 2) Qual o grau de consciência de classe [class consciousness]? 3) A estrutura de classes está refletida nos arranjos governamentais? 4) A estrutura de classes está refletida no sistema de dominação e subordinação? 5) Como as divisões religiosas na sociedade estão relacionadas com a vida econômica e política? 6) Como as divisões étnicas na sociedade e como estão relacionadas com a vida econômica e política? 7) Quais os modelos aceitáveis de conduta social? 8) Quais as várias tendências intelectuais ou escolas de pensamento? 9) Quais são seus temas centrais? 10) De que modo estes temas estão relacionados com as lutas sociopolíticas do período? 11) Podemos nos referir às raízes sociais do conflito intelectual? 12) As linhagens intelectuais refletem as divisões de classe ou outras clivagens sociais? (SILVA, 2016, p. 99).
} 
Repúblicas Socialistas Soviéticas, por um conflito ideológico e pela disputa pela hegemonia do poder (ARRAES, 2015). Ambas as potências políticas divergiam entre si no que diz respeito à cultura, economia, política.

[...] a qualificação de "fria" foi dada pela ausência de batalhas diretas entre os dois contendores, uma vez que a corrida armamentista levada a cabo por ambos ocasionou um nível bélico que levou à consciência do Assured Mutual Destruction, ou a certeza de que uma batalha direta levaria a uma destruição mútua. Nesse sentido, as batalhas ocorreram em regiões disputadas por um ou outro, distantes de seus territórios nacionais e por exércitos locais apenas guiados ou auxiliados por EUA ou URSS (ARRAES, 2015, p. 26).

Arraes (2015) considera que a Guerra Fria, no seu nível cultural, impulsionou o forjamento de uma cultura pretensamente global, baseada no American Way of Life, declarando como objetivo o combate ao projeto civilizador comunista, representado pela União Soviética, por meio de ações muito bem articuladas que possibilitaram uma construção imagética que não se restringia apenas à comunidade interna, mas também a diversos países os quais se buscava influenciar. À medida que se compreende isso, os argumentos utilizados por Arendt em "Verdade e Política" tornam-se um pouco mais claros, pois, justamente nesse texto, ela discute e problematiza a "política" - e nem assim poderia ser chamada - que é organizada e que se dá com base na construção de "imagens" que não visam apenas enganar o inimigo, mas a todos, inclusive aqueles que estão "dentro" da sociedade imagética, que passam a acreditar nela e a se tornarem vítimas de suas próprias mentiras.

Sobre as perguntas da primeira etapa, relacionadas às tendências intelectuais e escolas de pensamento que marcaram esse período, pode-se citar: o neopragmatismo; o behaviorismo - marcando, sobretudo, a Ciência Política e o estudo da Teoria Política; o estruturalismo; o existencialismo; a fenomenologia; o marxismo. A autora dialoga - às vezes, explicitamente - com algumas dessas correntes, especialmente com o behaviorismo, que pregava a necessidade de desenvolver uma Ciência Política mais "prática", "empírica", "objetiva", e que, uma vez reconhecido como paradigma científico, relegou o estudo da Filosofia Política e da Teoria Política a uma posição secundária. Essas duas últimas disciplinas foram desvalorizadas e consideradas "pré-científicas", uma vez que não se enquadravam nos "critérios neopositivistas" dos quais se revestia a Ciência Política daquele período. Hannah Arendt, inclusive, é uma das teóricas que, de acordo com Gunnel (1981), assim como Leo Strauss, Eric Voegelin e Sheldon Wolin, pode ser considerada representante da corrente normativa de defesa à Teoria Política.

\section{Aspectos relacionados à biografia da autora ${ }^{6}$}

É importante mencionar que, para o contextualismo social, é fundamental “integrar" os principais eventos da vida da autora na compreensão de que ela foi uma pessoa que viveu em uma sociedade na qual existiam conflitos importantes dos quais ela tinha consciência.

De origem judaico-germânica, Hannah Arendt, filha de Paul Arendt e Martha Arendt (cujo sobrenome de solteira era Cohn), nasceu em Linden, Hanôver - na Alemanha, em 14 de outubro de 1906. Após a morte de seu pai, Martha, sua mãe, foi a responsável por sua educação. Prodigiosa, já na juventude Arendt teve contato com as obras de Kant. Quando ainda vivia em Königsberg, ela teve aula de grego com Richard Harder, um filólogo clássico. Iniciou a sua graduação em Filosofia, Teologia e Filosofia Clássica no semestre de inverno de 1924/25 na Universidade de Marburg, onde Heidegger

\footnotetext{
${ }^{6}$ As questões da Tabela 2 - Aspectos relacionados à biografia que permitem situar o autor na sociedade - são: Quem era a família do teórico e quais suas conexões familiares? Como foi sua educação e sua formação intelectual? Quem eram seus amigos e associados? Sua educação? Sua religião? Sua situação econômica? Qual a sua profissão, ofício ou ocupação? Quem era seu empregador ou patrão? Qual era seu estatuto legal? Quais suas funções econômicas reais? Quais as fontes e a extensão de sua renda? Como era seu modo de vida? Quais suas atividades políticas? Quais suas afiliações políticas? Quais seus laços religiosos? Qual o gênero, identidade, orientação sexual (heteronormatividade)? Qual sua "etnia" e qual a situação dessa na sociedade em questão? (SILVA, 2016, p. 100).
} 
lecionava desde o semestre de inverno de 1923/24. Em 1926, Arendt vai para a Universidade de Freiburg, onde estuda com Edmund Husserl, e, depois, segue para a Universidade de Heidelberg para estudar com Karl Jaspers, onde permanecera até o ano de 1929, quando conclui a sua tese de doutorado - intitulada O conceito de Amor em Santo Agostinho, sob a orientação de Jaspers.

Em Da Dignidade da Política: Sobre Hannah Arendt, texto introdutório de Entre o Passado e o Futuro’, Celso Lafer a descreve como uma representante da cultura Weimar. A República de Weimar - período compreendido entre 1919 e 1933 - foi o governo instituído na Alemanha ao final da Primeira Guerra Mundial, após a deposição do Kaiser Guilherme II - o seu nome se deve ao fato de a Constituição da nova república ter sido celebrada na cidade de Weimar, na Turíngia.

A sua infância e desenvolvimento se deram em meio ao cenário da Primeira Guerra Mundial, sua maturidade em meio à República de Weimar, atravessando, ainda, o período de ascensão e de queda do nacional-socialismo. Pouco antes da Segunda Guerra, Arendt foi exilada da Alemanha, seu país de origem. Viveu, por conta do exílio, na França e, depois, nos Estados Unidos. Apesar de pertencer a uma família judia, ela não esteve muito engajada nos movimentos sionistas. Em 1950, em uma carta endereçada a Martin Heidegger, ela afirma que não se sentia nem uma mulher alemã e nem uma mulher judia, apenas a "a moça que veio de longe".

Ao longo de sua vida, Hannah Arendt exerceu diversas funções ligadas a sua trajetória como pesquisadora e professora de Teoria Política, bem como àqueles temas que tanto a inquietavam no cenário político de sua época. Por volta de 1950, por exemplo, atuou como "Executive director" da Jewish Cultural Reconstruction, viajando para a Alemanha e outros países europeus para encontrar e inventariar os bens culturais (sobretudo, exemplares de bibliotecas) judeus que haviam sido roubados e surrupiados pelos nacional-socialistas. Ela também trabalhou como avaliadora de textos originais da Editora Schocken, em Nova York. Em 1958, ela foi aceita como membro correspondente da Academia Alemã de Linguagem e Poesia. Além disso, apesar de, em 1967, ter conseguido uma posição fixa como "university professor" na Graduação da New School for Social Research, Hannah Arendt continuou comprometida com os seus antigos colegas e estudantes da Universidade de Chicago (Committee on Social Thought) e se dispôs a dar preleções em janeiro de 1970 em conjunto com os seminários sobre "pensar". Pouco antes disso, ela recebeu da Loyola University um título de honra, ligado ao comprometimento de uma apresentação e de uma participação em um colóquio. Em junho de 1972, ela recebeu um convite para participar como conferencista das Gifford Lectures, na Universidade de Aberdeen, ocasião que aproveitou para fazer uma espécie de teste dos dois volumes já em preparação de A Vida do Espírito - o "pensar" e o "querer".

O círculo social de Arendt se compunha de intelectuais, artistas, poetas. Em suas correspondências pessoais conseguimos encontrar diversos nomes como, por exemplo, Heinz Lichtenstein, um psiquiatra que também foi aluno de Heidegger; Hilde Fränklin, uma grande amiga sobre quem escreveu, algumas vezes, a Martin Heidegger, dando a entender que eles se conheciam - o poema "Morte" de Martin Heidegger foi escrito para ela; Arendt também estabeleceu uma amizade duradoura com Hans Jonas que sobreviveu, inclusive, ao afastamento de Jonas em relação a ela por conta do livro "Eichmann em Jerusalém". Ele também estudou em Marburg, como Arendt. Doutorou-se em 1928 sob a orientação de Heidegger e Bultmann. Já cedo se engajou com o sionismo. Ademais, Jonas lecionou na New School for Social Research de 1955 até a sua aposentadoria, onde tornou a encontrar Arendt.

Deve-se mencionar, também, Dolf Sternberger, que Arendt o conhecia do seu tempo de estudante e foi sua amiga até o fim da vida - depois da guerra deu-se também uma ligação profissional entre eles, de modo que as primeiras publicações de Arendt em língua alemã surgiram na revista Die Wandlung, que era por ele organizada; o seu professor e orientador, Karl Jaspers; John Glenn Gray, com quem matinha relações profissionais e de amizade; o casal Mary McCarthy e James West - Mary foi a

\footnotetext{
${ }^{7}$ Editora Perspectiva, 6. ed.
} 
responsável pela organização póstuma de The Life of the Mind, e também foi quem escreveu o posfácio da edição norte-americana.

No seu rol de amigos também constam o teólogo evangelista, Paul J. Tillich, que pertencia à Liga dos Socialistas; e Joan Stambaugh, que, inclusive, esteve em posse do trabalho de Lichtenstein durante sua atuação como tradutora, e com quem Arendt passou algum tempo. Sobre Stambaugh, ela afirma "essas moças talentosas têm uma dificuldade profunda em refletir seriamente, uma dificuldade tanto maior quanto menos dispostas elas se mostram, sobre todos esses questionamentos feministas que foram lançados em uma confusão absurda pelo movimento das mulheres” (LUDZ, 2001, p. 145).

Entre a lista do círculo social de Arendt, consta, ainda, seu primeiro marido, Günter Stern. Eles se casaram em 1929, logo depois se separaram. Para Arendt não foi um casamento por amor. Em 1937 se divorciaram, mas passaram a vida inteira em contato. Além de Stern, o seu segundo marido, Henrich Blücher, a quem Arendt conheceu no exílio, em Paris, e com quem se casou em 1940. Por meio de Blücher, ela conheceu e tornou-se amiga de Hermann Broch, sobre quem escreveu uma conferência intitulada "Hermann Broch e o Romance Moderno". A morte de Broch a abalou profundamente.

A todos estes nomes, por fim, soma-se Martin Heidegger, de quem foi aluna, amante e amiga. A ligação intelectual entre Arendt e Heidegger nunca teve fim - eles continuaram trocando correspondências a respeito de seus trabalhos, obras, temas de investigação etc., até o final de suas vidas, totalizando cinquenta anos de amor, amizade e admiração. Eles se conheceram no auditório número onze da Antiga Universidade de Marburg, onde Heidegger apresentou, no Semestre de Inverno de 1924/25, durante quatro horas, "O Sofista de Platão". Mais tarde, Arendt também conheceu Elfride Heidegger, a esposa de Martin, com quem manteve uma relação cordial e até amistosa, após um encontro "revelador" entre ambas.

\section{Aspectos relacionados ao ideal humano da autora}

Por não se tratar propriamente de uma obra completa, mas de um ensaio no qual Arendt aplica conceitos que ela desenvolve em outros textos, responder às questões relacionadas ao ideal humano da autora se constituíram, a princípio, como uma dificuldade ${ }^{8}$. Para Arendt, em "Verdade e Política", o tipo humano que carrega a melhor promessa para o futuro é aquele que é capaz de aceitar o passado e o mundo tal como eles são, reconhecer que o presente é resultado desse passado e agir para transformar esse "mundo" tendo em vista apenas o futuro. Será que esse ser humano - com essa capacidade - seria mais provável em uma classe social específica? Esse tipo de "aceitação do passado" seria algo resultante de algum tipo de formação elitista? A política autêntica só poderá se concretizar quando for um fim em si mesma e ocorrer a partir da estabilidade relativa do mundo e do espaço público, preservando a alegria de estar uns com os outros, em condição de pluralidade e liberdade.

Uma observação importante que deve ser feita com relação a esta etapa da pesquisa é que perguntas como "Como o teórico pensa que os seres humanos devem ser e agir?" e "Que tipo de ser humano deve dominar a sociedade?" não estão formuladas de maneira adequada para serem aplicadas à teoria política Hannah Arendt porque: a) o ideal humano da autora não se refere a um tipo de ser humano que deva "dominar" a sociedade, visto que o termo "dominar" não faz parte daquilo que ela compreende por política; b) ela não se propõe a dizer como os seres humanos devem agir, pois, para que a ação seja autêntica, tem de ser livre, espontânea e imprevisível, chegando a compará-la, na obra intitulada "A Condição Humana", de 1978, com a realização de "milagres". Caberia então analisar quais os requisitos

\footnotetext{
${ }^{8}$ As questões da Tabela 3 - Aspectos relacionados ao ideal humano - herói e anti-herói do teórico clássico são as seguintes: Como o teórico pensa que os seres humanos devem ser e agir? Que tipo de ser humano deve dominar a sociedade? Que tipo humano - real ou imaginado - carrega a melhor promessa para o futuro? Como o teórico visualiza o indivíduo que mais plenamente realiza esse potencial humano? Quem na sociedade como está atualmente constituída é mais capaz de atingir esse ideal? Esse ideal é atingível por qualquer um ou apenas por poucos? O abismo entre os homens que existem e o ideal humano é grande ou pequeno? Sob quais condições pode o ideal humano ser mais rapidamente realizado? (SILVA, 2016, p. 101).
} 
para que alguém conseguisse manifestar tal capacidade. Estar em uma posição subalterna afeta a capacidade de ser livre, espontâneo e imprevisível? Ou esse tipo de ação é possível para qualquer pessoa independente do contexto social?

\section{Prescrições para a realização do ideal humano}

As questões sobre as prescrições para a realização do ideal humano também não puderam ser respondidas porque não cabem ao pensamento arendtiano e, menos ainda, ao texto analisado. O principal obstáculo encontrado é a forma como tais perguntas estão colocadas: "Quem deve governar?", "Quem deve ser governado?", "Como os governantes devem governar?", "Como os governados devem obedecer?". A compreensão de Arendt a respeito da política é inspirada na experiência da polis préplatônica; não está baseada na dicotomia entre "governantes" e "governados", isto é, entre aqueles que "comandam" e aqueles que "obedecem" - na verdade, é precisamente essa noção de política que ela se dedica a combater. A política - a Esfera Pública, propriamente dita - requer igualdade entre os pares e pressupõe a pluralidade humana.

Referente às duas últimas perguntas que compõem esta etapa - "Quão grande é a distância que existe entre a situação sociopolítica real na qual o teórico está escrevendo e sua visão de uma ordem cívica reconstituída na qual seu ideal humano típico pode florescer?" e "Como essa lacuna pode ser preenchida?" - constata-se, tomando por base o próprio texto analisado, que a distância é grande. Arendt, vivendo o auge da Guerra Fria - uma maneira de conduzir a política sustentada por propagandas, imagens e baseada na tentativa cabal de destruir o que ela chama de "verdade fatual", conclama aos seus leitores que reconheçam a relevância da função política exercia por aqueles que, ao longo dos tempos, dispuseram-se a contar a verdade, a dizer o que é, a preservar o mundo. Esse seria o primeiro passo para que a lacuna fosse preenchida - respeitar o passado.

\section{Especificidades históricas das ideias do autor}

Ao longo do desenvolvimento dessa etapa surgiu um questionamento sobre uma das perguntas que a compunham: será que é, de fato, possível responder por que Arendt escreveu o que escreveu e com quais interesses? A teórica não afirma, de modo explícito, nenhum interesse e tampouco a análise da conjuntura social na qual estava inserida e de sua biografia contribuíram para que fosse possível fazer afirmações desse tipo - ao menos, não com as fontes que se tinha disponível para a realização do presente trabalho. Ainda assim, algumas considerações foram realizadas.

Arendt, no ensaio analisado, procurou, mais uma vez, ressaltar a importância de uma vida política fundamentada na pluralidade dos seres humanos, como já o havia feito em outros de seus artigos, ensaios e livros - só assim esse âmbito pode ser "autenticamente" chamado de público. O que chama a atenção é que ela tenha procurado fazer isso a partir de um espaço que considera "externo" à política, ou seja, da perspectiva da verdade.

A verdade, conforme Arendt (2007), possui uma força e um caráter despótico que lhe são próprios; é coercitiva por sua natureza; está além do acordo. Por se tratar de algo que não se pode manipular conforme o nosso bel-prazer, a verdade é odiada pelos tiranos e não é vista com bons olhos por aqueles governos que assentam sobre o consentimento. Considerando a "verdade fatual", a autora afirma que:

Podem-se discutir opiniões inoportunas, rejeitá-las ou chegar a um compromisso acerca delas, porém fatos indesejáveis possuem a enfurecedora pertinácia de nada poder demovê-los a não ser mentiras cabais. O estorvo é que a verdade fatual, como qualquer outra verdade, pretende peremptoriamente ser reconhecida e proscreve o debate, e o debate constitui a própria essência da vida política (ARENDT, 2007, p. 299). 
À medida que fatos e eventos - que já são de conhecimento público e, portanto, constituem parte do mundo que está entre os homens e proscreve o debate no âmbito público - são negados ou alterados de forma deliberada, para corroborar com a criação de uma "imagem" com intuito de monopolizar opiniões e prever ações futuras, o senso de realidade das pessoas é afetado, o "mundo" deixa de conferir estabilidade à vida humana, o passado e o presente são trazidos para a mesma condição de potencialidade do futuro. Em seu ensaio, Arendt procurou denunciar os perigos de se apagar a linha divisória entre "fatos" e "opiniões, e mostrar que, embora o âmbito da verdade corresponda ao modo de existência solitário do ser humano - isto é, a um modo de existir que é antipolítico e que se dá na singularidade, há uma relação íntima entre ele e o âmbito público - que corresponde ao modo de existência plural do ser humano, à política. A verdade possui uma "função política" e deve ser preservada.

Arendt se dá conta de que o ataque àquelas verdades fatuais consideradas inoportunas não é uma característica exclusiva dos regimes totalitários e ditaduras, onde eram tratadas como "tabu", ou seja, precisamente como aquilo que não eram - segredos. Nos países ditos "livres", a autora observa que essas verdades, embora fossem toleradas, eram transformadas em opinião e, portanto, perdiam a sua força para coagir - "[...] como se o fato do apoio da Alemanha a Hitler, ou o colapso da França ante as foras alemãs em 1940, ou a política do Vaticano durante a Segunda Guerra Mundial não fossem questão de registro histórico e sim uma questão de opinião" (ARENDT, 2007, p. 293).

\section{Estrutura básica dos argumentos}

De acordo com o que descreve sua amiga Mary McCarthy, no posfácio de "A Vida do Espírito", Hannah Arendt se preocupava muito com o leitor comum, por isso adotava uma forma de comunicação fácil e acessível; mas, para ela, o "leitor comum" era o estudante adulto. A quantidade conceitos empregados e as referências - diretas ou indiretas - feitas às obras canonizadas do pensamento político e, também, a outras obras próprias fazem com que seu texto seja direcionado a um público que possui maior conhecimento sobre a tradição ocidental de Teoria Política - sua argumentação é complexa e racional; não demonstra estar interessada em apelos emocionais e, menos ainda, em mover qualquer tipo de audiência para uma ação imediata ou extrema. Vale a pena reforçar que, para Arendt, a ação está intimamente relacionada com espontaneidade.

\section{Identificação dos destinatários da autora}

Arendt não direciona, de modo explícito, o ensaio "Verdade e Política", a nenhum "grupo" ou "classe" e mesmo considerando que ela estava, de certa forma, engajada nos conflitos políticos de seu tempo, sobre os quais se dedicou a escrever, esta parte da pesquisa não pôde, todavia, ser desenvolvida.

Importante mencionar, no entanto, que em uma nota que precede o ensaio, Arendt afirma que tinha como objetivo esclarecer duas controvérsias que se apresentaram após a publicação de Eichmann em Jerusalém: primeiro, sobre se é ou não sempre legítimo dizer a verdade; e o segundo, a respeito de "mentiras" professadas sobre o que ela havia escrito e sobre os fatos que havia relatado. Controvérsias essas que surgem em um contexto intelectual caracterizado por confrontos e debates (in)diretos.

\section{Análise textual de "Verdade e Política"}

Hannah Arendt inicia o seu célebre "Verdade e Política" afirmando que é um "lugar-comum" conceber a relação entre a "verdade" e a "política" como conflituosa e questionando:

Por que é assim? E o que isso significa, por um lado, para a natureza e dignidade da verdade e da veracidade? É da essência mesma da verdade o ser impotente e da essência mesma do poder o ser embusteiro? E que espécie de realidade a verdade possui, se é impotente no âmbito público, que, mais que qualquer outra esfera da vida humana, assegura a realidade da existência a homens sujeitos 
a nascimento e morte - isto é, a seres que sabem ter surgido do não-ser e que, após curto intervalo, novamente nele desaparecerão? E, por fim, não será a verdade impotente tão desprezível como poder que não dá atenção à verdade? (ARENDT, 2007, p. 283).

A autora, logo na primeira parte do texto, assinala que as razões de sua investigação foram mais políticas do que filosóficas e, portanto, permitiu-se desconsiderar a questão sobre o que é a verdade; ela salienta, ainda, que, por conveniência, utilizou a moderna distinção entre as verdades de tipo "racional" - ou seja, aquelas que são produzidas pela mente humana, como as verdades matemáticas, científicas e filosóficas - e as verdades de tipo fatual.

O conflito entre "verdade" e "política" é articulado, pela primeira vez, em relação à verdade racional e surge historicamente com a distinção entre dois modos de vida fundamentalmente opostos, isto é, o modo de vida do filósofo - aquele que busca a verdade - e o modo de vida do cidadão na polis grega - marcado pela instabilidade e pelo fluxo constante das opiniões (ARENDT, 2007). Tradicionalmente, as opiniões foram compreendidas como o oposto imediato à verdade e tratadas como "erros" ou "ilusões". Essa característica é o que confere a esse conflito sua dimensão política, porque "é a opinião e não a verdade que pertence à classe dos pré-requisitos indispensáveis a todo poder" (ARENDT, 2007, p. 289). De acordo com Arendt (2007), o antagonismo entre a filosofia e a política foi elaborado por Platão como o antagonismo entre duas formas de comunicação, o "diálogo" característica do filósofo - e a "retórica" - característica do demagogo que persuade a multidão.

Segundo Arendt (2007), esses dois "modos de vida" são opostos porque um diz respeito ao homem no singular enquanto o outro diz respeito aos homens no plural. A "verdade" do filósofo é obtida pelo homem em sua singularidade, na solidão, num diálogo consigo mesmo, por meio do raciocínio de sua própria mente, correspondendo, portanto, a um modo existência não político por natureza. As opiniões, por outro lado, correspondem à pluralidade humana, à convivência com os outros, à instabilidade do mundo e dependem do consentimento, sendo a força de uma opinião medida pelo número de pessoas que aderem a ela.

Quando o filósofo deseja que a sua verdade predomine sobre as opiniões do vulgo, ele tem de sofrer um deslocamento de um modo de vida para outro e disputar a legitimidade na esfera pública por meio da persuasão, do convencimento.

$\mathrm{Na}$ eventualidade, ligeiramente menos improvável, de que sua verdade predominasse sem o auxílio da violência, simplesmente porque, por acaso, os homens coincidissem nela, ele teria obtido uma vitória de Pirro, porquanto a verdade deveria seu predomínio, nesse caso, não à sua própria qualidade compulsiva, e sim ao acordo da multidão, que poderia mudar de ideia no dia seguinte e convir em alguma outra coisa; aquilo que fora verdade filosófica ter-se-ia tornado mera opinião(ARENDT, 2007, p. 305).

Os últimos vestígios do antigo antagonismo entre a verdade filosófica e as opiniões da esfera pública desapareceram - a moderna separação entre Igreja e Estado fez com que a "verdade revelada" da religião deixasse de interferir nos negócios do mundo, ou seja, na política; e a filosofia deixou de reclamar os seus direitos (ARENDT, 2007). Tanta tolerância com respeito a diversas opiniões sobre assuntos religiosos ou filosóficos poderia nos levar a concluir que o conflito foi resolvido, o que é rotundamente contrariado pela autora. Para Arendt (2007), o embate entre "verdade fatual" e "política", testemunhado a partir do século XX nas sociedades ocidentais, assume feições bastante análogas àquele que o precede - e esse é o objeto de sua investigação em Verdade e Política.

As verdades fatuais são de maior importância política porque "fatos e ventos - o resultado invariável de homens que vivem e agem conjuntamente - constituem a verdadeira textura do domínio político" (ARENDT, 2007, p. 287). Isso significa que o conflito já não se dá entre dois modos de vida diferentes, antes acontece dentro de um mesmo terreno. Por ser encontrada em solidão, a verdade filosófica transcende o âmbito dos negócios humanos - se penetra na praça pública, altera a sua natureza e se transforma em opinião. Outro é o caso da verdade fatual, pois essa sempre diz respeito a eventos e 
circunstâncias nas quais muitos são envolvidos (PEREIRA, 2018), ou seja, ao que acontece entre os homens constitui o mundo e, portanto, a "realidade" comum a todos nós. Fatos e opiniões, portanto, não são antagônicos; eles pertencem a um mesmo domínio - os fatos informam as opiniões, isto é, o pensamento político (ARENDT, 2007).

Ainda que, igualmente, pertençam ao âmbito público e estejam intimamente relacionadas, a verdade fatual se opõe à opinião em seu modo de asseverar a validade, carregando dentro de si o mesmo elemento de coerção que toda verdade possui e que coloca as suas afirmações além do acordo, da disputa, da persuasão e do consentimento (PEREIRA, 2018). Os fatos, uma vez estabelecidos, "possuem a enfurecedora pertinácia de nada poder demovê-los a não ser mentiras cabais" (ARENDT, 2007, p. 298). Precisamente isso é o que distingue a "verdade fatual" da "verdade racional" - o seu oposto não é o "erro" ou a "ilusão", mas a falsidade deliberada. "Fatos" são entidades muito mais frágeis que teorias e axiomas (ARENDT, 2007). Eles são estabelecidos pelo testemunho de várias pessoas que percebem e analisam a mesma ocorrência sob diferentes pontos de vista. Para que não sejam esquecidos, é necessário que as pessoas falem sobre eles, isto é, que eles sejam narrados como uma história.

Ao contrário da afirmação fatual, a falsidade deliberada não precisa estar inserida em um contexto para adquirir importância política. De acordo com Arendt (2007), ela é política por natureza, porque consiste numa tentativa de alterar o registro histórico, de transformar o mundo e, portanto, de agir; nasce do desejo de que as coisas fossem diferentes do que são. A capacidade humana de mentir é, na concepção da autora, um dos poucos dados demonstráveis que confirmam a nossa liberdade. Ao passo que contar a verdade - isto é, enunciar fatos, dizer o que é - conduz a uma postura inativa, de aceitação das coisas como elas são, mentir é uma ação política por excelência.

Jamais se incluiu a veracidade entre as virtudes políticas, pois ela de fato pouco contribui para esta
transformação do mundo e das circunstâncias, que é uma das mais legítimas atividades políticas.
Somente quando uma comunidade adere ao mentir organizado por princípio, e não apenas em relação
a particularidades, a veracidade como tal, sem o apoio das forças distorsivas do poderio e do interesse,
se torna fator político de primeira ordem. Onde todos mentem acerca de tudo que é importante
aquele que conta a verdade começou a agir; quer saiba ou não, [...] terá dado um primeiro passo para
a transformação do mundo (ARENDT, 2007, p. 310).

Arendt (2007) diferencia a mentira política tradicional daquilo que ela chama de mentira moderna, ou seja, a manipulação em massa de fatos e opiniões. A mentira tradicional, a seu ver, referia-se a segredos autênticos ou a intenções, seu objetivo era ocultar - ou manter ocultos - dados que nunca haviam de tornado públicos. A mentira moderna, por outro lado, lida com aquelas coisas que são do conhecimento de todos; diz respeito ao mundo que compartilhamos uns com os outros, à nossa realidade comum. São mentiras que carregam, dentro de si, a violência, visando destruir completamente aquilo que decidiram negar (PEREIRA, 2018).

Outra diferença entre essas duas formas de mentir, assinala Arendt (2007), é que as mentiras tradicionais se referiam a particularidades e se dirigiam a um inimigo, não a todas as pessoas; enquanto as mentiras modernas exigem um rearranjo completo dos fatos, ou seja, que seja criada outra realidade, como uma "imagem" de propaganda, e têm como consequência não apenas o engano do adversário, mas também a autoilusão, sendo o mentiroso enganado por próprias mentiras. Somente o autoengano cria a "aura de veracidade" que requer a mentira organizada de modo que ele é tolerado e até permitido nas sociedades de massas (PEREIRA, 2018).

Embora o pretendam, essas mentiras - ou pseudofatos - nunca chegam a se tornar um substituto adequado para a realidade, porque elas têm de ser constantemente alteradas a fim de salvaguardar as imagens criadas e manter a sua plausibilidade - sempre que as circunstâncias se modificam, livros de história, enciclopédia, obras de consulta e até certos nomes devem desaparecer ou serem substituídos (ARENDT, 2007). O resultado dessa situação de "instabilidade" não é que as mentiras passem a ser aceitas como verdade ou a verdade seja difamada como uma mentira, mas a destruição do nosso sentido 
de realidade - mediante o qual os homens se orientam no mundo. Visto que as possibilidades da mentira são ilimitadas, ela não pode competir, em questão de estabilidade, com a verdade fatual.

Aqueles que criam "imagens" se equivocam ao pensar que, alterando o registro histórico, isto é, mentindo sobre os fatos, poderão antecipar as transformações no mundo, pois não é o passado - e toda verdade fatual diz respeito ao passado, nem o presente, na medida em que esse é resultado do passado, mas o futuro que está aberto à ação humana (ARENDT, 2007). Quando passado e presente são tratados como partes do futuro, o âmbito público é privado de sua principal força estabilizadora e do ponto de partida para iniciar algo novo (agir).

A análise que Arendt faz sobre a política, nesse ensaio, dá-se, como ela mesma ressalta, a partir de um âmbito que é exterior ao dos negócios humanos, onde convivemos com os nossos pares, em comunidade - ela considera o espaço público a partir da perspectiva da verdade, assumindo um dos vários modos de existência solitária dentre os que ela cita, que são: "a solidão do filosofo, o isolamento do cientista e do artista, a imparcialidade do historiador e a independência do descobridor de fatos, da testemunha e do relator" (ARENDT, 2007, p. 320).

Arendt (2007) compreende que esses modos de existência solitária diferem, entre si, em muitos aspectos, mas têm em comum a circunstância de que, enquanto perdura, não permite nenhum compromisso político ou aderência a uma causa; e eles são comuns a todos os homens. Tal imparcialidade advém da particularidade de que a verdade seja buscada, obtida e contada a partir dessa posição externa em relação ao domínio político. "Essa é a raiz de toda a chamada objetividade - essa curiosa paixão, desconhecida exteriormente à civilização, pela integridade intelectual a qualquer preço. Sem ela, ciência alguma jamais poderia ter existido" (ARENDT, 2007, p. 323).

Cumpre assinalar que a realidade, na concepção arendtiana, não é a soma de fatos e eventos e "dizer a verdade" - sobre os fatos - é mais do que trazer informações, como fazem os jornalistas. Aqueles que se dispõem a contar verdade, a dizer o que é, a narrar os fatos, contribuem para a permanência e a estabilidade do "mundo" - mundo esse que compartilhamos, que se interpõe entre nós, no qual agimos, no qual aparecemos, sobre o qual falamos. Embora seja exterior ao domínio político, a verdade está intimamente relacionada à sua sobrevivência.

Aquele que diz o que é - légei tá eónta - sempre narra uma estória, e nessa estória os fatos adquirem algum sentido humanamente compreensível. [...] Na medida em que o contador da verdade dos fatos é também um contador de estórias, ele efetiva aquela "Reconciliação com a realidade" que era compreendida por Hegel, o filósofo da história par excellence, como o fim último de todo pensamento filosófico e que, de fato, tem sido o motor secreto de toda Historiografia que transcende a mera erudição. (ARENDT, 2007, p. 323).

O contador da verdade desempenha a função política de ensinar a aceitarmos as coisas como elas são - o mundo como ele é, as relações humanas que o compõem, aquilo que herdamos dos que vieram antes nós e legamos aos que virão depois. "Dessa aceitação, que também poderia ser chamada de veracidade, surge a faculdade do julgamento" (ARENDT, 2007, p. 323, relacionada à nossa capacidade de formar opiniões. Retomando as questões apresentadas por Hannah Arendt, no início de seu ensaio, pode-se inferir que a dignidade da verdade, apesar de sua impotência frente aos negócios humanos, reside na sua contribuição com a sobrevivência e a permanência do mundo.

Arendt (2007) pretende demonstrar, assim, que a esfera pública, não obstante a sua grandeza, não abarca a totalidade da existência do homem; ela é limitada por aquelas coisas que não podemos modificar à nossa vontade. Somente respeitando esses "limites" esse âmbito pode permanecer intacto, transcender a mortalidade humana, preservar a sua integridade, manter as promessas que nos une. 


\section{Resultados e discussões}

A pergunta que originou a presente pesquisa foi: Será que a realização da contextualização social de Hannah Arendt altera a interpretação do ensaio "Verdade e Política", de 1967? Ou, ainda, será que a interpretação do referido texto a que se chega, por meio do contextualismo social, é diferente da que se chegaria, por exemplo, por meio de outras propostas contextualistas, como a de Quentin Skinner, por exemplo? Será que esse texto poderia ser compreendido adequadamente sem a necessidade de recorrer a nenhuma referência ao seu contexto de produção, tal como a proposição de Leo Strauss? Será que o contextualismo social, de Neal Wood e Ellen Meiksins Wood, de fato, avança em relação à abordagem marxista ortodoxa?

Cumpre reconhecer que muitas das informações a respeito da configuração política da época, seus conflitos sociais e econômicos, bem como da biografia da autora - respectivamente etapa 1 e 2 da contextualização - contribuíram de maneira significativa para compreender porque Arendt escreveu o que escreveu, isto é, suas motivações, seu envolvimento pessoal com o contexto com o qual se deparava; e mesmo para entender o porquê de ocupar-se mais de alguns temas em detrimento de outros - como o feminismo, por exemplo, que não se constituiu como uma prioridade para a autora ao longo de sua trajetória intelectual.

Assim, a pergunta original dessa pesquisa teve de ser reformulada: Embora o contextualismo social possa contribuir com a compreensão de quem foi Hannah Arendt e a relação imbricada entre suas ideias e os conflitos sociopolíticos e econômicos de sua época, ele é realmente "essencial" para a interpretação da mensagem contida no texto analisado? Afinal, compreender por que um autor escreveu o que escreveu não é o mesmo que compreender o que ele escreveu. Em outros termos, a dúvida que se coloca é: seria o contextualismo social uma etapa imprescindível para a interpretação de um texto de Teoria Política ou uma etapa complementar?

Segundo Strauss (2015), a "história" só é indispensável para a compreensão de um texto na medida em que ele não é autoexplicativo e um texto que exige o uso de bibliotecas inteiras para ser interpretado não merece sobreviver ao tempo - não merece ser lido. Ele admite que há casos em que se apresenta a necessidade de buscar informações extrínsecas, mas, nesses casos, "o intérprete deve procurar reconstituir o seu pano de fundo do ponto de vista daquilo que o autor indicou como indispensável para compreensão de seu texto" (PEREIRA, 2018, p. 120). O contexto deve ser reconstituído, portanto, a partir de declarações explícitas e pistas deixadas pelo próprio teórico, como as que Hannah Arendt deixou no ensaio aqui analisado, mencionando fatos, eventos e pessoas aos quais atribuiu relevância naquele período.

Outra observação feita por Strauss (2015) é que mesmo a forma de ler o texto deve ser encontrada nele próprio. Para tanto, deve-se procurar conhecer os hábitos de leitura do autor porque, em geral, as pessoas escrevem como leem. "Tais hábitos se fazem conhecidos quando o autor deixa alguma indicação sobre eles no próprio texto ou dedica parte de seu tempo a discursar sobre como deve ser lida determinada obra" (PEREIRA, 2018).

Faz-se, então, uma objeção à postura de indiferença que o intérprete que opta pelo contextualismo social assume em relação a questionar de qual forma o próprio autor gostaria de ser lido e a tentar desenvolver a análise de seu texto a partir de seus próprios pressupostos. Apesar de se pretender menos "ortodoxo" em relação a outras abordagens marxistas, esse método carrega um forte viés ideológico, direcionando as perguntas a serem feitas a um texto antes mesmo de ele haver sido compreendido.

No que tange à análise feita ao ensaio "Verdade e Política", de Hannah Arendt, notou-se que algumas das perguntas, tal como estavam formuladas, não poderiam ser adequadamente aplicadas ao pensamento político da teórica e, no caso de que o fossem, não permitiriam que o texto e a própria autora falassem por si mesmos. 
Diante do exposto, surge, ainda, outros questionamentos: Será que todos os textos de pensamento político devem ser lidos da mesma forma, isto é, partindo das mesmas premissas, orientando-se pelo mesmo método? Os diálogos de Platão devem ser lidos da mesma forma que os escritos de Karl Marx? Qual é a diferença entre Filosofia Política e Teoria Política? Será que os textos de Filosofia Política devem ser lidos da mesma forma que os textos de Teoria Política? O que é, realmente, "importante", para a análise de um texto de Teoria Política? Qual é o nosso interesse ao estudar essas obras? Pretendemos compreender as ideias e as proposições de um autor ou traçar biografias de "heróis" do pensamento político - histórias protagonizadas pelos autores de determinadas obras? Será que saber com detalhes quem foi a autora, ou autor, modifica a forma como abordamos as ideias contidas no texto?

De acordo com Neal Wood e Ellen Meiksins Wood, no caso de pensadores clássicos da política, considerados parte do cânone - aqueles que são considerados clássicos - quando é realizada uma contextualização social meticulosa, os vínculos dos autores com grupos específicos e interesses "aparecem" e sua influência no conjunto da obra fica evidente. Ambos mostraram isso em estudos que explicitaram os vínculos "de classe" de autores como Sócrates, Platão, Aristóteles, Cícero, Maquiavel, Locke, Hobbes, Rousseau, Espinosa, entre vários outros que costumam ser lidos como se estivessem expressando apenas "reflexões" sobre a realidade política de seu tempo. Mas será que isso é válido para todos os autores e autoras? Será que existe a possibilidade de um texto ser motivado pelo desejo de compreender a política e não de defender a visão de um grupo específico? Ainda assim, será que tal motivação pode livrar um autor ou autora de sua relação efetiva com os conflitos do período em que viveu e escreveu sua obra?

\section{Considerações finais}

A proposta metodológica de Neal Wood e Ellen Meiksins Wood, apesar da sua pretensão de avançar em relação à abordagem marxista ortodoxa e de superar outras como o contextualismo linguístico e o textualismo, apresentou limitações quando aplicada ao pensamento de Hannah Arendt, expresso no ensaio "Verdade e Política". Cabe mencionar que uma das dificuldades reside no fato de que reconstituir o contexto social, a biografia, analisar com detalhe a obra completa do autor ou autora (para compreender melhor seu "ideal humano", por exemplo) é uma tarefa coletiva, quase impossível de ser realizada por apenas uma pessoa no tempo que se dispõe para completar um trabalho acadêmico.

Por um lado, o contextualismo social contribui com a missão de reunir conhecimentos tanto sobre a obra como sobre quem foi o seu autor, permitindo conceber o ser humano como uma unidade pensante-atuante - ou seja, busca-se a reconciliação de dois aspectos do conhecimento político que, conforme Pereira (2019), outrora, foram divorciados a fim de promover uma ciência "empírica", "objetiva", "neutra" da política: o "teórico" e o "prático".

Observou-se, no entanto, que a compreensão da mensagem contida no texto analisado em pouco - ou em quase nada - foi alterada após o trabalho de contextualização. Por isso, retoma-se a pergunta: Será que, de fato, é "essencial" realizar a contextualização social de um autor para interpretar as suas ideias? Será que o contexto relevante não é aquele que se encontra, à maneira straussiana, seguindo apenas as orientações e pistas que o próprio autor considerava importante e deixou explicitadas ao longo de seu texto? Com isso, não se pretende questionar a importância de adquirir conhecimento histórico e biográfico sobre os teóricos da política ou sobre a época em que viveram. A pergunta é pela imprescindibilidade dessa tarefa no que se refere à interpretação dos textos desses teóricos. Será que quando esses autores escreveram o que escreveram o fizeram de forma limitada, direcionando-se exclusivamente aos seus contemporâneos? Ou, como disse Leo Strauss, pretendiam-se "patrimônio de todas as épocas"? Será que a compreensão das ideias apresentadas em um texto não pode ser adequadamente acessada por meio dele próprio? Além disso, será que todos os textos de Teoria Política devem ser igualmente lidos e interpretados, isto é, compreendidos a partir do mesmo método, utilizando os mesmos recursos, procurando responder às mesmas perguntas? 
Porém, fica ainda a questão a respeito de se essa conclusão pode ser generalizada ou se sua aplicação diz respeito apenas ao estudo realizado: a mensagem do texto "Verdade e Política" de Hannah Arendt pode ser compreendida mesmo sem que se realize uma contextualização social meticulosa da autora e da obra. Mas será que isso vale para toda a obra da autora? E será que vale para outros autores e autoras? As aplicações realizadas pelos proponentes do método mostraram que, quando a contextualização é realizada, o sentido do texto pode ser alterado - ou seja, a mensagem é compreendida de forma diferente caso o texto seja lido sem que se situe autor e obra no contexto.

Ainda, uma contextualização social que seja realizada por alguém que não compartilha com os proponentes do contextualismo social as "premissas" - que são claramente marxistas - conduz a um resultado diferente daquele encontrado por quem já inicia seu estudo convencido de que todo autor ou autora é um "ator" politicamente engajado no conflito de sua sociedade - sendo que a economia tem primazia sobre outras variáveis?

Esses questionamentos nos autorizam a considerar que, nesse sentido, em alguns casos, a proposta textualista de Leo Strauss garante mais liberdade, em relação ao contextualismo social, para que o autor e o texto falem por si próprios, compreendendo que as informações extrínsecas ao textos só precisam ser buscadas nos casos em que o leitor se depara com pistas ou afirmações explícitas que o conduzam a isso, porque a mensagem do texto - o seu significado - deve estar contida nele próprio, tal qual o autor quis revelar e expressar no e para o mundo.

\section{Referências}

AMADEO, Javier. Teoria Política: Um Balanço Provisório. Revista de Sociologia e Política, v. 19, n. 19, p. 17-34, 2011.

ARENDT, Hannah. Entre o passado e o futuro. São Paulo: Perspectiva, 2007.

ARRAES, Marcos Alexandre de Melo Santiago. Tramas do olhar: Americanismo, Guerra Fria e a emergência de um novo regime visual no Brasil entre 1945 e 1964. 232f. 2015. Tese (Doutorado em História) - Universidade Federal de Santa Catarina, Florianópolis, 2015.

CARDOSO, Juliane Cristina Helanski; SILVA, Vania Sandeleia Vaz da; NERES, Magella Geraldo. Como estudar teoria política: textualismo, contextualismo linguístico e contextualismo social. V Simpósio Paranaense de Ciências Sociais, 5., 2016. Anais... Toledo: Universidade Estadual do Oeste do Paraná, 2016, pp. 63-85.

GUNNEL, John. Teoria Política. Brasília: Editora Universidade de Brasília, 1981.

LUDZ, Ursula (Org.). Hannah Arendt - Martin Heidegger: Correspondência 1925/1975. Trad. Marco Antonio Casanova. Rio de Janeiro: Relume Dumará, 2001.

PEREIRA, Mariana da Silva. História do Pensamento Político: Contribuições metodológicas de Quentin Skinner. V Simpósio Paranaense de Ciências Sociais, 5., 2016. Anais... Toledo: Universidade Estadual do Oeste do Paraná, 2016, pp. 46-62.

. Verdade e Política: Diálogo entre as teorias de Hannah Arendt e Leo Strauss. 2018. Trabalho de Conclusão de Curso (Graduação em Ciências Sociais) - Universidade Estadual do Oeste do Paraná, Toledo, 2018.

PEREIRA, Mariana da Silva; SILVA, Vania Sandeleia Vaz da. Contextualismo social: poder e política na obra "A Condição Humana" (1958) de Hannah Arendt (1905-1975). 5 Encontro Anual de Iniciação Científica e Inovação da Unioeste, 5., 2019. Anais... Cascavel: Universidade Estadual do Oeste do Paraná, 2019. 
Uma leitura de "Verdade e Política" de Hannah Arendt pelo método textualista de Leo Strauss. VI Simpósio Paranaense de Ciências Sociais, 6., 2018. Anais... Toledo: Universidade Estadual do Oeste do Paraná, 2018, p. 110-132.

ROCKMAN, Bert. Política nos Estados Unidos: Tendências nas últimas quatro décadas. Estudos Avançados, v. 8, n. 21, p. 51-77, 1994.

SILVA, Ricardo. Identidades na Teoria Política: Entre a ciência, a normatividade e a história. Pensamento Plural, a. 2, n. 3, p. 9-21, 2008.

SILVA, Vania Sandeleia Vaz da. O contextualismo social de Neal Wood e Ellen Meiksins Wood: uma introdução. V Simpósio Paranaense de Ciências Sociais, 5., 2016. Anais... Toledo: Universidade Estadual do Oeste do Paraná, 2016, pp. 86-110.

STRAUSS, Leo. Perseguição e a arte de escrever: e outros ensaios de filosofia política. São Paulo: É Realizações, 2015. 